\title{
Research on a Carbon Reduction Optimization Model for a Megalopolis Based on Land-Use Planning and ICCLP Method
}

\author{
Ze-sen Wang ${ }^{1}$, Lin Liu' ${ }^{1}$ Zheng $\mathrm{Xu}^{2}$, Zhuang $\mathrm{Li}^{3}$, $\mathbf{Y u ~ L i}^{1 *}$ \\ ${ }^{1}$ MOE Key Laboratory of regional Energy Systems Optimization, Resources and Environmental Research Academy, \\ North China Electric Power University, Beijing 102206, China \\ ${ }^{2}$ School of Electrical and Electronic Engineering, North China Electric Power University, Beijing 100012, China \\ ${ }^{3}$ Changsha Vocational College of Environmental Protection, Changsha 410004, China
}

Received: 21 March 2014

Accepted: 3 September 2014

\begin{abstract}
For the primary purpose of minimizing carbon dioxide emissions in a megalopolis, an optimization model that remarkably reduces carbon emissions for the megalopolis, which is based on the inexact chanceconstrained linear programming (ICCLP) method and incorporates interval linear programming (ILP), and chance constrained programming (CCP), has been constructed. The corresponding net emissions of carbon dioxide results in probability levels of default equalling $p_{i}=0.01,0.05,0.1$ are $[1,383.379,1,825.311] \times 10^{4}$, $[1,357.728,1,800.841] \times 10^{4},[1,338.671,1,780.060] \times 10^{4}$ tons in the megalopolis in 2015 . Besides, the areas of different types of carbon-sinkable land of various cities within planned regions are obtained. The volume of energy consumption of dominating energy consumption industries in planned regions equals [965.52, $1,136.79] \times 10^{4}$ tons, which is reduced by $[14.97,22.09] \%$, while the intensity of energy consumption is decreased by $[18.00,20.00] \%$ compared with that in 2010 . Meanwhile, the intensities of carbon emissions are reduced by $20.00 \%, 19.00 \%$, and $18.08 \%$, respectively, under the conditions of $p_{i}=0.01,0.05,0.1$. It meets the requirements that carbon intensity shall be cut down by $17.00 \%$ in 2015 compared with that in 2010, which was proposed by “The $12^{\text {th }}$ Five-Year Initiative of Controlling Greenhouse Gas Emissions.' The annual average GDP growth rate is $12.20 \%$, reaching $9.79 \times 10^{11}$ yuan in total, higher than the expected annual growth rate of $10 \%$ in accordance with the development objective of " $12^{\text {th }}$ Five-Year" plan.
\end{abstract}

Keywords: low-carbon economy, uncertainty, interval-chance constrained, land planning, optimization model

\section{Introduction}

A report from the intergovernmental panel on climate change (IPCC) of the United Nations demonstrates that energy consumption and inappropriate land-use planning are the sources of man-made carbon emissions [1]. It has been illustrated that the carbon emissions coming from

*e-mail: liyuxx8@hotmail.com energy burning accounts for approximately $80 \%$ of the total carbon emissions in China [2], proving that energy consumption is the uppermost source of carbon emissions. As urban carbon emissions take up $75 \%$ of global carbon emissions [3], low-carbon urban construction is the key to the reduction of greenhouse gas emissions. Therefore, in line with the low-carbon economy, proper planning in terms of energy consumption and the types of land use are believed to significantly reduce the dual-stress of development of 
society as well as the constraints from energy conservation and emission reduction in a holistic way. It will not only bring residents a healthy living environment, but also can be beneficial to the sustainable development strategy to the largest extent.

It has been widely focused and studied on the impact of energy consumption and land use on carbon emissions. However, the relationship between energy consumption, land use, and carbon emissions has been overlooked [4-6]. In the existing natural resources, technical resources, and the distribution and allocation of human resources, the reasonable planning and utilization of land will not only increase the land carbon sink effect, but also help mitigate the carbon emissions brought by energy consumption. On the one hand, existing research into low-carbon urban planning are mainly based on a deterministic model $[6,7]$ without taking uncertain factors such as the emissions of industries in low-carbon economy development planning, carbon emissions cuts, etc., into consideration.

On the other hand, the differences between long-term development laws of land use in a low-carbon megalopolis and the actual development paces, as well as decision-making risks, are ignored. Interval chance-constrained linear programming (ICCLP) can not only obtain the solution in the form of random variables subjected to certain probability density distribution in the actual case, but also can help effectively cope with the parameter uncertainty in models and analyze the solutions under different levels of risks, thereby supporting the decision-making process for regional low-carbon economy development planning, lowering the risks of decision-making.

Taking energy consumption, carbon emissions, and carbon-sinkable land area as constraint conditions, introducing ICCLP [8] on a background case of Wang et al. [9], this paper constructs a carbon reduction optimization model based on land-use planning and the ICCLP method. This model helps analyze and study the major energy-consuming industries' energy consumption, as well as the areas of different types of carbon-sinkable land use, which provides a sound basis for the low-carbon development of megalopolis.

\section{Construction of Megalopolis Carbon Reduction Optimization Model}

\section{Interval Linear Programming}

Moore first advanced the Interval Analysis Method in 1966 , in view of the calculation errors in the automatic control process. Later, Huang set forth a series of interval programming theories [10-12]. ILP shows its superiority for the sake of convenience and economy by using the uncertainty of intervals, so that less information is required to get the upper and lower limit of variables.

The basic expressions of Interval Programming Method are as follows:

$$
\operatorname{Max} f^{ \pm}=C^{ \pm} X^{ \pm}
$$

The constraints:

$$
\begin{gathered}
A_{i}^{ \pm} X^{ \pm} \leq B_{i}^{ \pm} \\
A_{i}^{ \pm} \in A^{ \pm}, B_{i}^{ \pm} \in B^{ \pm}, i=1,2, \ldots, m \\
x_{j}^{ \pm} \geq 0, x_{j}^{ \pm} \in X^{ \pm}, j=1,2, \ldots, n
\end{gathered}
$$

...where: $A^{ \pm} \in\left\{R^{ \pm}\right\}^{m \times n}, B^{ \pm} \in\left\{R^{ \pm}\right\}^{m \times 1}, C^{ \pm} \in\left\{R^{ \pm}\right\}^{1 \times n}$, $X^{ \pm} \in\left\{R^{ \pm}\right\}^{n \times 1}$.

\section{Chance-Constrained Programming}

Chance-Constrained Programming (CCP) is used to solve stochastic programming problems that may exceed model constraints. Its core is to not require that all constraints containing random information are $100 \%$ satisfied. It allows parts of constraint conditions in specific cases to be violated as long as the degree of violation is under control.

The basic expressions of CCP method are as follows:

$$
\operatorname{Max} f=C(t) X
$$

The constraints:

$$
\begin{gathered}
\operatorname{Pr}\left[\left\{t \mid A_{\mathrm{i}}(t) X \leq b_{i}(t)\right\}\right] \geq 1-p_{i} \\
A_{\mathrm{i}}(t) \in A(t), b_{i}(t) \in B(t), i=1,2, \ldots, m \\
\mathrm{X} \geq 0, p_{i} \in[0,1]
\end{gathered}
$$

...where $A$ is a fixed value and $B$ is a random variable. The cumulative distribution function of $B$ is $F\left(b_{i}\right), b_{i}(t)^{p_{i}}=\mathrm{F}^{-1}\left(\mathrm{p}_{\mathrm{i}}\right)$.

The Construction of Objective Function and the Determination of Constraint Conditions of Carbon Emissions Reduction Optimization Model

\section{Construction of the Objective Function of Carbon Emissions Reduction Optimization Model}

For the primary purpose of minimizing net carbon emissions in key cities, an ICCLP and land-use-planningbased optimization model that remarkably reduces carbon emissions for the megalopolis is constructed in this study. The constructed model is capable of greatly reducing the decision-making risks brought up by all those uncertainties and, as a result, the stability and reliability of the model are guaranteed.

The model can be expressed as follow:

$$
\min f^{ \pm}=\sum_{m=1}^{M} \sum_{h=1}^{H} E_{m h}^{ \pm} \times F_{h}^{ \pm}-\sum_{m=1}^{M} \sum_{k=1}^{K} S_{m k}^{ \pm} \times G_{m k}^{ \pm}
$$

...where $f^{ \pm}$is the net emissions in the megalopolis in 2015, and the unit is ton $(t) ; m$ is the area of city; $h$ is the main energy consumption industry; $k$ is the carbon-sinkable landuse type; $E_{m h}$ is energy consumption by the end of the plan of $h$ industry in $\mathrm{m}$ city; $F_{h}^{ \pm}$is the carbon emissions coefficient of $h$ industry, and the unit is $\mathrm{t} / \mathrm{t} ; S_{m k}^{ \pm}$is the carbon sink area of the land-use type $k$ for city $m$ by the end of the fiveyear plan, and the unit is $\mathrm{km}^{2} ; G_{m k}$ is the capability of car- 
bon sequestration while adopting different planting patterns on land type $k$ by the end of the five-year plan, where the unit is $\mathrm{t} / \mathrm{km}^{2}$.

\section{Determination of the Constraints of Carbon Emissions Reduction Optimization Model}

a) Energy consumption constraint:

In order to avoid the situation of unitary energy consumption by the end of the plan, the energy consumption of all types in planned areas should be properly controlled as the nation requests so that all industries in the area can function as usual. Namely:

$$
E_{\text {min }}^{ \pm} \leq E_{m h}^{ \pm} \leq E_{\text {max }}^{\stackrel{ \pm}{ }} \quad \forall m, h
$$

b) Energy consumption intensity constraint:

This meets the goal of energy consumption reduction that was put forward in "The National Greenhouse Gas Emissions Control Initiative in '12 $2^{\text {th }}$ Five-Year' Planning." It can be expressed as follows:

$$
\begin{aligned}
& \sum_{m=1}^{M} \sum_{h=1}^{H} E_{m h}^{ \pm} / G D P^{ \pm} \leq L E C I^{ \pm} \times\left(1-X^{ \pm}\right) \\
& L E C I^{ \pm}=\sum_{m=1}^{M} \sum_{h=1}^{H} B E_{m h}^{ \pm} / B G D P^{ \pm}
\end{aligned}
$$

...where $X^{ \pm}$is the energy consumption intensity reduction by the end of the plan, and the unit is $\%$; $L E C I^{ \pm}$is the energy consumption intensity in base period of the plan, t/million yuan; $B G D P^{ \pm}$is the sum of the city $G D P$ in base period of the plan, million yuan; $B E_{m h}$ is the volume of energy consumption in planned area for industry $h$ in city $m$ in base period, $\mathrm{t}$.

c) Carbon emissions constraint:

The actual carbon emissions in planned areas by the end of the plan should be lower than the target carbon emissions set in the base period:

$$
\sum_{m=1}^{M} \sum_{h=1}^{H} E L_{m h}^{ \pm} \leq \sum_{m=1}^{M} \sum_{h=1}^{H} B E L_{m h}^{ \pm} \times\left(1-Z^{ \pm}\right)
$$

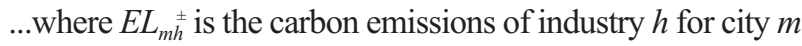
by the end of the plan, $\mathrm{t} ; B E L_{m h}{ }^{ \pm}$is the actual carbon emissions of industry $h$ for city $\mathrm{m}$ in base period of planning, $\mathrm{t} ; Z^{ \pm}$is the target carbon emissions reduction by the end of the plan, $\%$.

d) Carbon emissions intensity constraint:

The intensity of carbon emissions should meet the corresponding requirements in the planned area by the end of the plan:

$$
\sum_{m=1}^{M} \sum_{h=1}^{H} E L_{m h}^{ \pm} / G D P^{ \pm} \leq L E L I^{ \pm} \times\left(1-Y^{ \pm}\right)
$$

...where $L E L I^{ \pm}$is the intensity of carbon emissions in base period of planning, $\mathrm{t} /$ million yuan; $Y^{ \pm}$is the percentage by which the carbon emissions intensity fall by the end of the plan, $\%$. e) GDP development constraint:

To ensure that the economy in the planned areas can steadily grow under the guidance of macro-economic planning, it can be expressed as follows:

$$
G D P^{ \pm} \geq B G D P^{ \pm} \times\left(1+\alpha^{ \pm}\right)^{5}
$$

...where $\alpha^{ \pm}$is the growth rate of economy for planned areas, $\%$.

f) Carbon sequestration constraints:

To date, the conflict between rapid urbanization and agricultural land use is becoming increasingly prominent, land use planning plays an increasingly important role in land use activities in the Chinese urbanization process. To deal with unexpected issues throughout the planning process, it is necessary for ICCLP to set a default probability $p_{i}$ for constraints that might be at certain probability risk, which exerts accurate limits on the constraints' default circumstances. In this paper, this model reasonably redistributes the area of carbon sink land type (forest land, farmland, grassland, urban landscape land), being a scientific solution to resolve the conflict between urbanization and carbon sink land-use. This can be expressed as follows:

$$
\begin{aligned}
& \operatorname{Pr}\left\{\sum_{m=1}^{M} \sum_{k=1}^{K}\left(\begin{array}{l}
\sum_{s=1}^{S} F S_{m s k}^{ \pm}+\sum_{j=1}^{J} C S_{m s k}^{ \pm} \\
+\sum_{g=1}^{G} G S_{m s k}^{ \pm}+\sum_{v=1}^{V} V S_{m s k}^{ \pm}
\end{array}\right) \leq T S^{ \pm}\right\} \geq 1-p_{i} \\
& \sum_{m=1}^{M}\left(\begin{array}{l}
\sum_{s=1}^{S} F G_{m s}^{ \pm}+\sum_{j=1}^{J} C G_{m j}^{ \pm} \\
+\sum_{g=1}^{G} G G_{m g}^{ \pm}+\sum_{v=1}^{V} V G_{m v}^{ \pm}
\end{array}\right)=\sum_{m=1}^{M} \sum_{k=1}^{K} G_{m k}^{ \pm}
\end{aligned}
$$

...where $p_{i}$ is used to constrain the probability of default; $T S^{ \pm}$ is the total carbon sink area of the megalopolis, $\mathrm{km}^{2} ; F S_{m s k}$, $C S_{m s k}^{ \pm}, G S_{m s k}^{ \pm}$, and $V S_{m s k}^{ \pm}$are the area of forest land, farmland, grassland, urban landscape land, respectively, $\mathrm{km}^{2} ; F G_{m s}^{ \pm}$, $C G_{m j}^{ \pm}, G G_{m g}{ }^{ \pm}$, and $V G_{m v}{ }^{ \pm}$are the carbon sequestration capability of forest land, farmland, grassland, urban landscape land, respectively, ton $/ \mathrm{km}^{2} ; s, j, g$, and $v$ are planting patterns of the forest land (trees and shrubs), farmland (wheat and paddy), grassland (natural turf), urban landscape land (artificial turf), respectively.

\section{The Case Overview}

The case megalopolis is located at where the BeijingGuangzhou economic zone, Pan-Pearl River Delta economic zone, and the Yangtze River economic zone join. It sits in the south central region in a province of China consisting of three prefecture-level cities with total area of about $2.8 \times 10^{4} \mathrm{~km}^{2}$. In 2007 this megalopolis was called "the comprehensive supplementary reforms pilot area of national resource saving and environment-friendly society construction.' In terms of its geographical location, natural 
Table 1. Energy consumption amounts of the five energy intensive industries for the case of the megalopolis (Unit: $10^{4}$ tons standard coal).

\begin{tabular}{|l|c|c|c|}
\hline \multicolumn{1}{|c|}{ Energy industry } & City 1 & City 2 & City 3 \\
\hline Industry of black metal smelting and rolling processing & {$[6.50,8.00]$} & {$[5.70,6.90]$} & {$[1.40,1.60]$} \\
\hline Industry of electricity, heat production and supply & {$[158.40,193.60]$} & {$[19.00,23.20]$} & {$[136.50,166.90]$} \\
\hline Nonmetal mineral products & {$[149.90,183.20]$} & {$[64.40,78.80]$} & {$[43.10,52.70]$} \\
\hline Chemical raw materials and products manufacturing & {$[24.60,30.00]$} & {$[34.90,42.70]$} & {$[49.30,60.30]$} \\
\hline Industry of colored metals smelting and pressing & {$[34.70,42.40]$} & {$[21.50,26.30]$} & {$[385.70,471.40]$} \\
\hline
\end{tabular}

Table 2. Land use type area of carbon sink available for the case of megalopolis (Unit: $\mathrm{km}^{2}$ ).

\begin{tabular}{|l|c|c|c|}
\hline \multirow{2}{*}{ Agricultural land type } & \multicolumn{2}{|c|}{ Available carbon sink area of land use types in base period } \\
\cline { 2 - 4 } & City 1 & City 2 & City 3 \\
\hline Cultivated land & {$[2,375.00,2,548.00]$} & {$[2,139.46,2,144.37]$} & {$[1,228.59,1,240.21]$} \\
\hline Forest land & {$[6,050.56,6,058.06]$} & {$[6,617.00,6,626.00]$} & {$[2,302.71,2,308.38]$} \\
\hline Grassland & {$[0.058 .55,0.062 .37]$} & {$[0.24,0.26]$} & {$[96.10,96.00]$} \\
\hline Urban landscape land & {$[199.31,209.85]$} & {$[32.82,33.12]$} & {$[0.86,0.88]$} \\
\hline
\end{tabular}

environment, resources, talents, and technologies, etc., the megalopolis shows its inherent advantages and possesses required fundamental conditions. They underlie the construction of low-carbon megalopolis and provide a rare opportunity for its development. Nevertheless, inappropriate industrial structure and energy consumption structure, environmental pollution and ecological damage are challenging the construction of low-carbon megalopolis construction [13].

For ages it has been high-energy-consumption industries that dominate the industrial development of megalopolis, and the overall energy consumption intensity seems high. Especially the black metal smelt and rolling process industry, nonmetal mineral products industry, and electricity industry. In 2008 the comprehensive energy consumption of 10,000 yuan GDP for three cities in the megalopolis averaged 1.36 tons of standard coal, which is above the province average and several times higher than that in the United States, Japan, and other developed countries. The megalopolis has put large-scale dual-type society construction into practice since 2007. It has been clear that the lowcarbon economy with principal characteristics like low energy consumption, low pollution, and low emissions is exactly what the dual-type society construction calls for. Statistical analysis reveals that carbon reserves are about $394 \times 10^{4}$ tons per year in current megalopolis forest ecosystem, from which it can be easily understood that the forest ecosystem plays an essential role in carbon sequestration. But beyond that, farmland, grassland, and urban landscape land also play an important role in carbon sequestration of the megalopolis due to their non-ignorable carbon sink capability. Hence, to maximize a forest vegetation's function of carbon sequestration is of great importance for lowcarbon megalopolis construction.

\section{Case Data Collection and Statistical Analysis}

The data in this research was extracted primarily from the statistical almanac of case cities as well as literatures relevant to megalopolis low-carbon economic projects [1416]. The missing data of specific years have been filled by the polynomial fitting method. The major energy-consuming industries' volume of energy consumption, the areas of carbon-sinkable land-use type for the case megalopolis, and the coefficient of carbon sequestration of vegetation under different land use types are shown in Tables 1-3, respectively.

In the low-carbon context of the case megalopolis, different land type areas of each city in megalopolis from 1986 to 2010 were selected, and the cumulative probability distribution of the carbon-sinkable land type area for every city was fitted by using Crystal ball (as shown in Fig. 1). Insight into the law of development of different land type in recent years can be gained through the distribution result, whereby future land development can be constrained. According to each city's carbon sink area of cumulative probability distribution, the total carbon sink area $T S\left(\mathrm{~km}^{2}\right)$ under three probabilities of default $\left(p_{i}=0.01,0.05,0.1\right)$ are shown in Table 3.

\section{Optimization Model Solving and Analysis}

\section{Model Optimization Results}

According to the volume of energy consumption, energy consumption intensity, and land use development pattern specified in the overall regional development plan of the case megalopolis, based on the previously introduced 
Table 3. The coefficient of carbon sequestration of vegetation under different land use types (Unit: tons $/ \mathrm{km}^{2}$ ).

\begin{tabular}{|c|c|c|c|c|c|}
\hline \multicolumn{2}{|c|}{ Forest land } & \multicolumn{2}{c|}{ Farmland } & Grassland & Urban landscape land \\
\hline Trees & Shrubs & Paddy & Wheat & Natural turf & Artificial turf \\
\hline 53.54 & 64.54 & 41.36 & 43.52 & 48.35 & 65.83 \\
\hline
\end{tabular}

optimization model of carbon emissions reduction, the energy consumption amount of main energy-consuming industries in the megalopolis in 2015 was obtained by using the IPCC-provided calculating method of carbon emissions [17] (Table 5). Table 6 reveals the net carbon emissions and the allocation of the carbon-sinkable land use type areas under different probabilities of default.

\section{Analysis of Experimental Results}

By means of the carbon emissions reduction optimization model for megalopolis based on the ICCLP method, the net carbon emissions of the case region in 2015 are $[1,383.38,1,825.31] \times 10^{4}$ tons, $[1,357.73,1,800.84] \times 10^{4}$ tons, and $[1,338.67,1,780.06] \times 10^{4}$ tons corresponding to
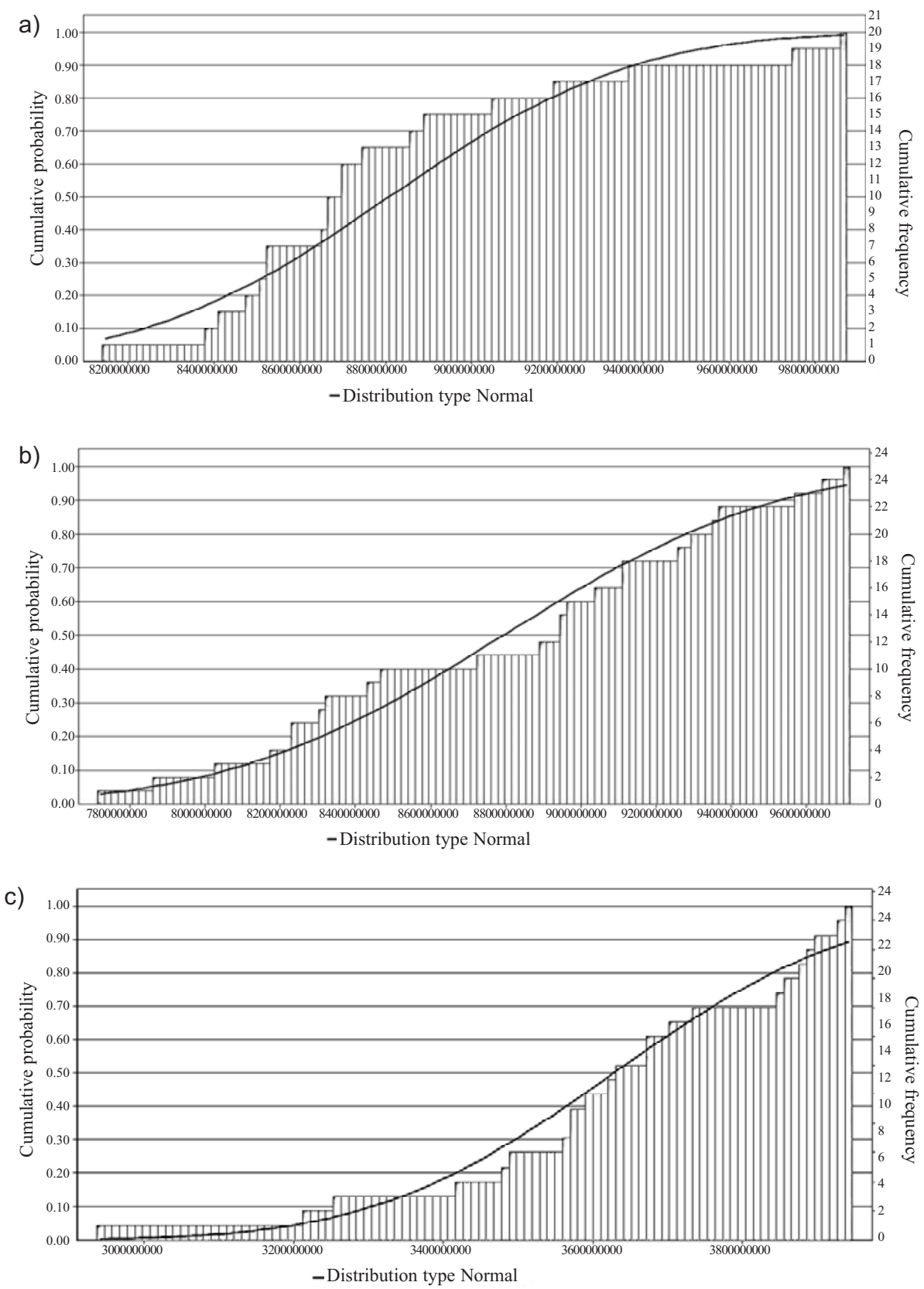

Fig. 1. Cumulative probability distributions of carbon sink available area for City 1 (a), City 2 (b), and City 3 (c). 
Table 4. Available carbon sink area for each city under different probability levels (Unit: $\mathrm{km}^{2}$ ).

\begin{tabular}{|c|c|c|c|}
\hline \multirow{2}{*}{ Probability levels } & \multicolumn{3}{|c|}{ Available carbon sink area in base period } \\
\cline { 2 - 4 } & City 1 & City 2 & City 3 \\
\hline$p_{i}=0.01$ & {$[8,103.66,8,105.12]$} & {$[7,673.68,7,681.68]$} & {$[2,911.54,3,001.68]$} \\
\hline$p_{i}=0.05$ & {$[8,170.03,8,183.85]$} & {$[7,821.68,7,823.71]$} & {$[3,210.03,3,215.84]$} \\
\hline$p_{i}=0.1$ & {$[8,231.11,8,235.43]$} & {$[8,047.37,8,050.31]$} & {$[3,302.70,3,310.29]$} \\
\hline
\end{tabular}

Table 5. The optimal energy consumption amounts of the five energy intensive industries for the case of megalopolis (Unit: $10^{4}$ tons standard coal).

\begin{tabular}{|l|c|c|c|}
\hline \multicolumn{1}{|c|}{ Energy industry } & City 1 & City 2 & City 3 \\
\hline Industry of black metal smelting and rolling processing & {$[4.88,6.40]$} & {$[5.52,7.68]$} & {$[1.05,1.68]$} \\
\hline Industry of electricity, heat production, and supply & {$[118.80,155.18]$} & {$[21.74,28.83]$} & {$[102.38,136.98]$} \\
\hline Nonmetal mineral products & {$[128.57,152.20]$} & {$[49.11,63.04]$} & {$[32.33,42.16]$} \\
\hline Chemical raw materials and product manufacturing & {$[26.40,45.65]$} & {$[26.18,34.16]$} & {$[36.98,48.24]$} \\
\hline Industry of colored metals smelting and pressing & {$[26.03,33.92]$} & {$[21.04,24.82]$} & {$[332.28,396.94]$} \\
\hline
\end{tabular}

the probability of default of carbon-sinkable land area, which are $0.01,0.5$, and 0.1, respectively. According to the target GDP and carbon intensity reduction objective where the case province set in the " $12^{\text {th }}$ Five-Year" Planning focusing particularly on the case megalopolis, and the actual GDP and carbon emissions in 2010, the expected value of carbon emissions reaches $5,014.62 \times 10^{4}$ tons. Through the case megalopolis, land use planning for the target of available carbon sink area and the carbon sink capacity of the four kinds of main land for carbon sequestration, obtained the target carbon sink value of land carbon sink under $12^{\text {th }}$ Five-Year Planning for megalopolis development requirements, and then obtained the net carbon emissions planning value of $2,895.66 \times 10^{4}$ tons in the cases of the megalopolis in 2015, total carbon emissions compared to the planning values fell by $[36.96,52.22] \%$, [37.81, $53.11] \%$, [38.52, 53.76]\% under $0.01,0.05,0.1$ probability levels, respectively. Compared to that paper [4] that established the deterministic optimization model to predict megalopolis net carbon emissions of about $1,800 \times 10^{4}$ tons in 2015, the ICCLP method solved the objective function value and part of the decision variables are interval value. When the probability levels are 0.01 and 0.05 , the net carbon emissions interval results in $[1,383.38,1,825.31] \times 10^{4}$ tons, $[1,357.73,1,800.84] \times 10^{4}$ tons, the upper bound is slightly larger than $1,800 \times 10^{4}$ tons, but $94.27 \%, 99.81 \%$ of net carbon emissions in interval span less than $1,800 \times 10^{4}$ tons. Considering the land use and the risk of probability level, optimization of interval value is superior to the deterministic optimization model of $1,800 \times 10^{4}$ tons; when the probability level is 0.1 , the net carbon emissions below what deterministic model optimization $[25.63,1.12] \%$. The method adopted by this paper will effectively decrease the net carbon emissions through the energy consuming indus- tries in the main megalopolis from the perspective of city planning. In addition, the model can be seen that as the probability level increase, but increasing carbon sink area corresponding to reduce industrial emissions cause the decline of megalopolis level of industrial development, improving the risk level of the low carbon economy sustainable development balance.

Compared with the actual carbon emissions intensity in 2010 , the optimized scheme falls by $20.00 \%$ when the probability level is 0.01 . When the probability level comes to 0.1 , the one in optimized scheme falls by $18.08 \%$. This degree of optimization is higher than not only the standard that carbon intensity should decrease by $17.00 \%$ in 2015 in "The $12^{\text {th }}$ Five-Year Initiative of Controlling Greenhouse Gas Emission,' but also the carbon intensity reduction requirement of $18.00 \%$ in "The $12^{\text {th }}$ Five-Year" Planning. After optimization, the megalopolis regional energy intensity declines by $[18.00,20.00] \%$ in 2015 compared with 2010, and the total energy consumption of main energyconsuming industries amounts $[965.52,1,136.79] \times 10^{4}$ tons, declined by $[14.97,22.09] \%$ compared with that in 2010 $\left([1,135.60,1,388.25] \times 10^{4}\right.$ tons). Among them, the energy consumption from industries of black metal smelting, rolling processing, and non-metal Mineral products manufacturing in City 1 and City 3, and the colored metals smelting, rolling processing, power and heat generating and supply in City 2 are significantly reduced, with the maximum decreasing rate of $25.00 \%$, which improves the megalopolis' situation of inappropriate industrial structure and energy structure. In addition, apart from meeting the needs for carbon emissions and energy consumption decline, the planned area has made sure that the economy could develop steadily and rapidly. In the model optimization scheme, the megalopolis GDP in 2015 will reach $9.79 \times 10^{11}$ yuan, 
Table 6. The optimal net carbon emission amounts and carbon sink available area allocation of the case of megalopolis under different probability levels.

\begin{tabular}{|c|c|c|c|c|c|c|}
\hline $\begin{array}{c}\text { Probability } \\
\text { levels }\end{array}$ & $\begin{array}{c}\text { The net carbon } \\
\text { emissions }\left[10^{4} \text { ton }\right]\end{array}$ & City & Forest land $\left[\mathrm{km}^{2}\right]$ & Cultivated land $\left[\mathrm{km}^{2}\right]$ & Grassland $\left[\mathrm{km}^{2}\right]$ & $\begin{array}{c}\text { Urban landscape } \\
\text { land } /\left[\mathrm{km}^{2}\right]\end{array}$ \\
\hline \multirow{3}{*}{$p_{i}=0.01$} & \multirow{2}{*}[1383.38,1825.31]{} & City 1 & {$[5,953.00,5,953.00]$} & {$[2,100.00,2,100.00]$} & {$[0.013,0.013]$} & {$[50.65,52.11]$} \\
\cline { 3 - 8 } & & City 2 & {$[6,173.58,6,181.58]$} & {$[1,464.27,1,464.27]$} & {$[0.27,0.27]$} & {$[35.56,35.56]$} \\
\cline { 3 - 8 } & & City 3 & {$[1,604.56,1,674.7]$} & {$[1,180,1,180]$} & {$[0.86,0.86]$} & {$[12.12,146.12]$} \\
\hline \multirow{3}{*}{$p_{i}=0.05$} & \multirow{2}{*}[1357.73,1800.84]{} & City 1 & {$[5,953.00,5,953.00]$} & {$[2,100.00,2,100.00]$} & {$[0.013,0.013]$} & {$[117.02,130.84]$} \\
\cline { 3 - 8 } & & City 2 & {$[6,321.58,6,323.61]$} & {$[1,464.27,1,464.27]$} & {$[0.27,0.27]$} & {$[35.56,35.56]$} \\
\cline { 3 - 8 } & & City 3 & {$[1,888.86,1,903.05]$} & {$[1,180.00,1,180.00]$} & {$[0.86,0.86]$} & {$[126.12,146.12]$} \\
\hline \multirow{3}{*}{$p_{i}=0.1$} & {$[1338.67,1780.06]$} & City 1 & {$[5,953.00,5,953.00]$} & {$[2,100.00,2,100.00]$} & {$[0.013,0.013]$} & {$[178.10,182.42]$} \\
\cline { 3 - 8 } & & City 2 & {$[6,547.27,6,550.21]$} & {$[1,464.27,1,464.27]$} & {$[0.27,0.27]$} & {$[35.56,35.56]$} \\
\cline { 3 - 8 } & & City 3 & {$[1,995.72,1,983.31]$} & {$[1,180.00,1,180.00]$} & {$[0.86,0.86]$} & {$[126.12,146.12]$} \\
\hline
\end{tabular}

with the average annual growth of $12.20 \%$, higher than the target annual growth of $10 \%$ articulated in "The $12^{\text {th }}$ FiveYear" Planning for megalopolis development.

In the case of ensuring the decrease of both carbon emissions intensity and energy consumption while the GDP steadily grows, the carbon-sinkable land area allocation strategy should be dynamically adjusted so as to obtain the areas of every carbon-sinkable land types under different probabilities of default. It can be seen from Table 6 that when the default probability level is 0.01 , the carbon sequestration land area in an optimized scheme is less than the average level in the past. With the increase of probability level, the net carbon emissions decline, adjusted for different land types available carbon sink area in the cities. The forest land and farmland are the main types of available carbon sink, with their area declined but carbon sink increased, which shows the unreasonable proportion of the land use before urban planning (the proportion of the area of trees and shrubs can be optimized by 1.21:1 in the forestland, and the proportion of the area of paddy and wheat can be optimized by $7.1: 1$ ). When the probability level reached 0.1 , the area of urban landscape land rapid enlargement in the City 1 and City 3, due to the amount of carbon sink per unit area of land used for urban landscape, is less than other agricultural land, and can indirectly reflect imbalance between urbanization development and the area of available carbon sink land.

Thus, it can be seen that the constructed optimization model has the ability to properly control the area of carbon sink, effectively decreasing the urban carbon emissions, adequately developing the unused land, and helping solve the issues like over urbanization and land wastage, etc.

\section{Conclusion}

This paper provided an optimized model for a city carbon reduction optimization model, which not only reduces the net carbon emissions, but also successfully predicts different net carbon emission corresponding to different default levels, energy consuming amounts of main energyconsuming industries among the megalopolis, and the proportion area of available carbon sink land by end of the $12^{\text {th }}$ five year. To be specific, it has been estimated that net carbon dioxide emissions will be reduced to $[1,383.379$, $1,825.311] \times 10^{4}$ tons, $[1,357.728,1,800.841] \times 10^{4}$ tons, $[1,338.671,1,780.060] \times 10^{4}$ tons, respectively, corresponding to the default probabilities of $0.01,0.05,0.1$ after optimization. This optimization scheme not only meets the requirements of greenhouse gas emissions reduction set forth by "The $12^{\text {th }}$ Five-Year Initiative of Controlling Greenhouse Gas Emission," which ensures the regional GDP growth and properly controls the area of carbon-sinkable land use within the megalopolis, but also takes into account the total carbon sink area under different levels of probability of default that might influence decision-making. It facilitates making more scientific decisions for decision makers when they are comprehensively leveraging risks of default. Furthermore, it paves the way for a steadily and rapidly developing megalopolis economy, along with optimizing energy structure and rationally planning carbonsinkable land. The construction of a "dual-type society" will also benefit substantially from it in the long run.

\section{Acknowledgements}

This study was supported by the Environmental Protection Science and Technology Project of Hunan Province (2011-04).

\section{References}

1. YU T. T., HAN C. L., XU G. C. Analysis on carbon source and carbon sink of different land use types of Liaoning province. Guangdong Agricultural Sciences. (2), 118, 2012.

2. YUAN X. L., ZHONG Y. Y. The practice and system construction of China low carbon City. Urban Studies. 17, (5), 42, 2010.

3. CAI Y. P., HUANG G. H., YANG Z. F., LIN Q. G., TAN Q. Community-scale renewable energy systems planning under 
uncertainty-An interval chance-constrained programming approach. Renewable and Sustainable Energy Reviews. 13, (4), 721, 2009.

4. YOU H. Y., WU C. F. Carbon emission efficiency and low carbon optimization of land use based on the perspective of energy consumption. Journal of Natural Resources, 25, (11), 1875,2010

5. YUAN X. L., FANG Y., ZHANG B. S. An analysis of dynamic econometric relationship between urbanization and energy consumption in Guan-Zhou cities. Urban Studies, 18, (3), 65, 2011.

6. ZHAO Y. Q., HUANG Z. J., ZHONG T. Y., CHUAI X. W. Carbon effect evaluation and low-carbon optimization of regional land use, Transactions of Chinese Society of Agricultural Engineering, 29, (17), 220, 2013.

7. CHRISTOPHER L. W., GLEN P. P., DABO G., KLAUS H. The contribution of Chinese exports to climate change, Energy Policy, 36, (9), 3572, 2008.

8. XIE Y. L., LI Y. P., HUANG G. H., LI Y. F., CHEN L. R. An inexact chance-constrained programming model for water quality management in Binhai New Area of Tianjin, China. Sci. Total Environ. 409, (10), 1757, 2011.

9. $\quad$ WANG L., SUN Z., LI Z., ZHAO W. J., LI Y. An optimal model for low-carbon urban agglomeration based on sustainable development of economy. society and environment. Renewable Energy Resources. 30, (8), 112, 2012.

10. HUANG G. H., MOORE R. D. GREY linear programming, its solving approach, and its application. International journal of systems science. 24, (1), 159, 1993.

11. HUANG G. H., LOUCKS D. P. An inexact two-stage stochastic programming model for water resources management under uncertainty. Civil Engineering and Environmental Systems. (17), 95, 2000.

12. HUANG G. H., BAETZ B. W., PATRY G. G. An interval linear programming approach for municipal solid waste management planning under uncertainty. Civil Engineering Systems. (9), 319, 1992.

13. ZUO L. F., CHEN L., LI H., HUANG Y. Some thoughts on construction of changsha-zhuzhou-xiangtan low-carbon urban agglomeration. China Collective Economy. 12, (4), 23, 2012.

14. Changsha statistical information network. Energy statistics yearbook 2010. http://www.cstj.gov.cn/ tjnj/2011/010.html.

15. Zhuzhou statistical information network. The first half of the energy consumption analysis. http://www.zztj.gov.cn/ninfo.as px?Nid=4485.

16. DENG M. J. Analysis on the Carbon Emission of Municipal-scale Industrial Enterprises in Xiangtan City. China Population, Resources and Environment. 21, (1), 64, 2012.

17. IPCC. 2006 IPCC Guidelines for National Greenhouse Gas Inventories: volume II. Japan: the Institute for Global Environmental Strategies. http://www.ipcc.Ch/ipccreports/ Methodology-reports.html. 2008. 